\title{
Objeto y sujeto en Siegfried Kracauer
}

\author{
[Object and Subject in Siegfried Kracauer] \\ http://dx.doi.org/10.11606/1982-8837233985
}

\section{Francisco Manuel García Chicote}

\begin{abstract}
This paper aims to explicit Siegfried Kracauer's concept of critique during the interwar period. It casts doubts on a currently widespread mode of interpretation, which claims to have found in his oeuvre significant traces of a postmodernism avant la lettre. The article examines Kracauer's changing ideas on the subject-object relation as the founding elements for his notions of critique. First, it analyses the philosopher's early anticapitalism within the frame of German Kulturkritik. Second, it features Kracauer's own ideological critique of the very Kulturkritik aspects he maintained until circa 1925. Finally, it examines the form of Kracauer's analysis of Modernity as conscious activations of categories that make up the objective structure of the historic world. Thus, it concludes that, in a way that turns out irreconcilable with postmodernist fashions, Kracauer derives his criterion of truth from the structure of the object.
\end{abstract}

Keywords: Postmodernism; Realism; Philosophy of Life; Weimar Republic; Marxism

Resumen: El trabajo intenta explicitar el concepto de crítica en la obra de Siegfried Kracauer durante el período de entreguerras. Pone para ello en entredicho una clave interpretativa generalizada que quiere todavía hoy encontrar en este filósofo a un teórico posmodernista avant la lettre. El artículo rastrea el desarrollo de la relación sujeto-objeto en la obra de Kracauer como malla configuradora de los respectivos conceptos de crítica de este. En primer lugar, se analiza la crítica anticapitalista de los primeros años de la década de 1920 como forma peculiar de la Kulturkritik. En segundo lugar, se caracteriza la crítica ideológica a la que el propio Kracauer somete la Kulturkritik a partir de aproximadamente 1925. Finalmente, se analiza la forma de la crítica a partir de 1925 como activación consciente de categorías que constituyen la estructura objetiva del mundo histórico. Se concluye así que en Kracauer, y de una manera irreconciliable con las lecturas posmodernistas, el criterio de verdad se halla condicionado por el polo objetivo.

Palabras clave: Posmodernismo; Realismo; Filosofía de la vida; República de Weimar; Marxismo

\section{Introducción: ¿Un observador posmodernista?}

El interés que la obra de Siegfried Kracauer (Frankfurt a. M. 1889 - Nueva York 1966)

ha suscitado en los últimos treinta años -luego de que pasara relativamente inadvertida

\footnotetext{
1 Universidad de Buenos Aires, Sección de Literaturas en Lenguas Extranjeras. E-mail: fgchicote@gmail.com. ORCID: 0000-0002-3267-390X
}

\section{(cc) BY-NC}

Pandaemonium, São Paulo, v. 23, n. 39, jan.-abr. 2020, p. 57-85 
CHICOTE, Francisco M. G. - Objeto y sujeto en Sigfried Kracauer

por casi medio siglo- destaca la persistente labor del ensayista frankfurtiano en tanto peculiar observador de la modernidad. Sobresale ante todo una presunta "preocupación de Kracauer por las verdades parciales, provisionales, relativas de la memoria cultural” que, al decir de Dagmar Barnouw, "va directo al corazón del modo en que, al final del siglo XX, comprendemos la modernidad" (1994: 19). ${ }^{2}$ Se trata, en efecto, de una declaración de actualidad que remite a una conexión establecida desde mediados de la década de 1980 -es decir, el momento del "resurgimiento" de Kracauer-por David Frisby, cuyos trabajos procuran comprender a Simmel, Walter Benjamin y el propio Kracauer como "sociólogos de la modernidad", y en relación a este último afirman que “junto con su ilustración del laberinto de la vida metropolitana [...], siguió también a Simmel en su aprehensión de los 'fragmentos fortuitos de la realidad' que revelaban los secretos ocultos de la modernidad" (FRISBY 1992: 203).

De manera sugestiva, una parte no menor del interés por la ensayística de este filósofo ha supuesto encontrar en ella rastros -confirmaciones, incluso anticipaciones conscientes- de lo que Terrence McDonald llamó a mediados de la década de 1990 en relación con las nuevas investigaciones en ciencias humanas un "giro histórico" y cuyo sustento filosófico resultaría de "un asalto a la noción de sujeto burgués unitario", una consideración suspicaz respecto de las cuestiones de "agencia y agente":

Agencia y agente han asumido por ello importancia crítica justamente en el momento en que el concepto de agente fue evacuado de mucho de su contenido. Más que un coloso que monta a horcajadas las páginas de la historia, el agente debe ahora emerger de esas páginas. De modo similar, el significado de la agencia debe emerger de la reconstrucción histórica de sus posibilidades, no de deducciones basadas en un mapa putativo de estructuras sociales y posiciones subjetivas acompañantes (1996: 6).

El modo de este giro asume un sesgo preponderantemente epistemológico, interesado más en las formas históricas de construcción de conocimiento que en la adecuación -o siquiera: orientación- objetiva de sus enunciados. No ha de sorprender pues que aquello que McDonald designa como “creciente autoconciencia histórica” de la intelectualidad de las últimas décadas del siglo pasado encuentre un modelo en el enfoque de la antropología interpretativa y sus “(de)construcciones” ulteriores, que por su parte encontraron un basamento filosófico en las posiciones abiertamente antiontológicas de Michel Foucault y Jacques Derrida. Independientemente de los avatares que el destino

\footnotetext{
${ }^{2}$ Cuando la versión citada no se halla en español, la traducción es nuestra. 
CHICOTE, Francisco M. G. - Objeto y sujeto en Sigfried Kracauer

deparó a los escritos de Clifford Geertz al interior de las reflexiones "metaantropológicas"3, permanece como elemento condicionante de la antropología interpretativa y con ella de la tendencia general de las ciencias humanas la preeminencia del carácter ficcional de la teoría (cf. GeERTZ 1973: 15; Clifford 1986: 4; Reynoso 1991: 30) y la adopción de categorías de retórica como herramientas de las constitución de aquello que, en la jerga foucaultiana, se llama "regímenes de verdad" (FouCAULT 1979: 189). José Sazbón ha señalado que este "retorno del sujeto como polo de atención teórica, centro de funciones e instancias judicativas" (2009: 135) pone en entredicho el condicionamiento objetivo del conocimiento (que se fundamenta en la prioridad ontológica del objeto ya señalada por Marx en sus manuscritos de París) y legitima "la soberanía de la perspectiva", que coloca tanto "un pluralismo de las operaciones de constitución" como, en contrapartida, una objetividad "negociada y transitoria", o “irrelativa" o "autoconfigurada" (SAZBÓN 2009: 136). Ejemplo de esto último es el modelo hermenéutico del discurso escrito con el que Paul Ricoeur (1973) propone la noción de texto como paradigma de las ciencias del espíritu y la noción de la lectura como forma básica de la interpretación en estas ciencias. Ricoeur encuentra en la escritura un modelo de epojé fenomenológica capacitada, gracias a la semiosis de sus propios procesos, para crear una objetividad en la que arraigue aquella pretensión de explicación que Wilhelm Dilthey solo veía posible en las ciencias de la naturaleza. La colocación del modelo textual como superación de la antítesis entre verstehen (comprender) y erklären (explicar) muestra en qué medida empero la "analogía textual" (GEERTZ 1983: 30) de Ricoeur anida aún en las adialécticas nociones diltheyanas de sujeto como valor vivo y de objeto como facticidad muerta.

La recuperación que se hizo de Kracauer a partir de los años ochenta del siglo pasado se halla signada por afinidades con esta corriente teórica. Señalemos cinco de ellas. Sobresale primero la certeza de que una de las signaturas salientes de la metódica del filósofo sería -o se asemejaría a- la "thick description" de la etnografía interpretativa. La conexión aparece ya en 1996 en Kracauer zur Einführung (Introducción a Kracauer),

\footnotetext{
${ }^{3}$ Paul Rabinow, de quien se hablará más adelante, ve con cierta sorpresa ya en 1986 que "el momento en que la profesión histórica está descubriendo la antropología cultural en la persona (no representativa) de Clifford Geertz, es justamente el momento en que Geertz está siendo cuestionado en antropología y afirma que la "diferencia fundamental" que el nuevo enfoque posmoderno presenta respecto del método de la descripción densa consiste en que esta tiene como objeto al otro, mientras que aquella se interesa por “descripción antropológica del otro" (RABINOW 1986: 241s.). 
CHICOTE, Francisco M. G. - Objeto y sujeto en Sigfried Kracauer

de Gertrud Koch, quien remite a las "descripciones densas del mundo laboral y vital del milieu de los empleados comerciales" (1996: 55), pero es indagada en profundidad por Mülder-Bach en 1998. "La razón por la cual el texto ha sobrevivido y puede ser leído de nuevo hoy”, dice Mülder-Bach en la introducción a la edición en lengua inglesa del libro sobre los empleados comerciales de Kracauer (Die Angestellten), se vincula con el hecho de que el autor ejercitaría la “"thick description' avant la lettre" en términos de Geertz (MÜLDER-BACH 1998: 17). Bajo este rótulo entiende la editora de las segundas y definitivas Werke (Obras completas) del filósofo las formas compositivas que darían cuenta de un "individualismo altamente autoconsciente que resiste la generalización metodológica e implica crucialmente la puesta en escena de la extranjería y la distancia" como condiciones del conocimiento (1998: 5).

Corolario de la perspectiva inaugurada por la descripción densa es una creciente preocupación por el carácter retórico de los discursos objetivistas (RABINOW 1986: 243s.) y un intento por explicitar y explorar las formas literarias de la investigación etnográfica, entendida ahora -y marcada por la lectura derrideana de la reflexión que Levi-Strauss hace de la actividad de escribir en Tristes Trópicos- principalmente en tanto "escritura" (cf. ClifFORD 1986: 2). En las interpretaciones de Kracauer, se trata de proponer la primacía de las formas sensoriales sobre el carácter abstractivo del concepto. MülderBach destaca, en una frase que bien podría insinuar cierta afinidad con La condición posmoderna de Jean François Lyotard, la aversión de Kracauer por el "grand récit” y los "grandes esquemas filosóficos" (MÜLDER-BACH 1998: 14), y Koch realza el "carácter literario" de la obra del filósofo, cuyas interpretaciones "se orientan más bien a una retórica de las metáforas que a una construcción conceptual” (КоCH 1996: 8).

Allí donde empero se postula la afinidad posmoderna de Kracauer con mayor intensidad es en la delimitación exclusivamente epistemológica de su praxis teórica, lo que implica lógicamente desterrar el problema del carácter objetivo del ser en tanto ser. En concordancia con la desaparición de la adecuación objetiva como criterio de verdad en las ciencias humanas y sociales, se insiste en que la obra de Kracauer "no se halla dirigida a la realidad como tal, sino específicamente a los fenómenos fugitivos e imperceptibles" (MÜLDER-BACH 1998: 10) y a los modos de representación: "No es la meta la imitación de la cosa, sino la imitación de la condición epistemológica. Si la realidad es una construcción de la conciencia, la representación debe ser igualmente una 
CHICOTE, Francisco M. G. - Objeto y sujeto en Sigfried Kracauer

construcción” (OSCHMANN 2009: 40). El supuesto arraigo de Kracauer en la perspectiva del constructivismo epistemológico de la segunda mitad del siglo XX (que circunscribe la actividad del sujeto cognoscente a los límites exclusivos de la conciencia) suele constatarse en una frase de las primeras páginas de Los empleados: "La realidad es una construcción" (KRACAUER 2008: 117): "Con esta conocida frase de Kracauer se ha abierto de un golpe el portal de entrada a su edificio metodológico y epistemológico" (HOFMANN y KORTA 1997: 20). La decidida separación del mundo que existe independientemente del sujeto que se divisaría en la textura de Kracauer ha llevado a Mülder-Bach a procurar formas textuales que recrean en la etnografía urbana del filósofo la epojé husserliana, cuyo rasgo fundamental es, como apunta Mülder-Bach, la "suspensión [...] de posiciones ontológicas” (MÜLDER-BACH 2015: 28).

Se trata, para parafrasear a Ricoeur (1997: 65), de un "kantismo sin sujeto trascendental", aunque en lugar del constreñimiento causado por un "formalismo absoluto", emergería aquí un sujeto tan fragmentario como refractario a cualquier "estilo paradigmático de conceptualización” (cf. SAZBóN 2009: 145). Resulta llamativo en este elemento, que la concepción de intelectual extraterritorial ("solitario", del "permanecer afuera") ( STALDER 2003: 3) que se le imputa a Kracauer coincida con la figura del “intelectual crítico cosmopolita" que Paul Rabinow propone para toda instancia cognitiva subjetiva consciente de que la verdad no depende de parámetros objetivos. Se trata de una "figura" cuyo "valor rector" es "ético": una postura "opositora suspicaz de poderes soberanos, verdades universales, afectaciones demasiado relativizadas, autenticidad local, moralismos por todos lados" (RABINOW 1986: 258). El "cosmopolitanismo" remite, en Rabinow, tanto al ser paria, como a la no identificación, al reconocimiento de la múltiple determinación, a la existencia intersticial, y a la sospecha constante que se traduce en una devoción por la retórica: es sugestivo que los sofistas griegos constituyan figuras típicas de este intelectual.

No es difícil advertir las afinidades que esta posición intersticial y radicalmente escéptica detenta con un temperamento "marcadamente democrático" que, de acuerdo con Geertz, ha de prepararse para "una situación a la vez fluida, plural, descentrada e insoslayablemente desprolija” (GEERTZ 1983: 19s.). En Kracauer, a la extraterritorialidad se le adscribe un pluralismo "decididamente no-ideológico" (STEINMEYER 2008: 10). 
CHICOTE, Francisco M. G. - Objeto y sujeto en Sigfried Kracauer

La situación descripta no agota naturalmente las reflexiones sobre Kracauer, pero es lo suficientemente poderosa como para marcar una tendencia. Independientemente de los no pocos hallazgos realizados por tales interpretaciones, cabe señalar que les corresponde a estas el común denominador de circunscribirse a cuestiones epistemológicas: tratan preeminentemente de elementos que en la obra de Kracauer conformarían cierta teoría original del sujeto cognoscente. Sin embargo, como el carácter objetivo de las categorías subjetivas de Kracauer no se somete a consideración, estos perfiles corren, lógicamente, el riesgo de asumir lo que Max Horkheimer designó en 1937 una "función social positiva", propia de los modos "tradicionales" de la teoría (HORKHEIMER 2008: 238) e independiente de su autoproclamada pretensión crítica. En términos generales, la crítica de Kracauer es concebida en tanto conceptualizaciones de la facultad del conocer, sin que las cuestiones relativas a la génesis de lo dado (historia) o a la transformación subjetiva de este (praxis) sean entendidas como factores condicionantes de tal facultad y por ende objetos de la crítica. Cuando historia y praxis ocupan la atención teórica, se intuye una tendencia al plano del irracionalismo, que remite el surgimiento de las categorías epistemológicas a la extraordinaria psicología de Kracauer, o al de la moral, según el cual los posicionamientos políticos del autor serían irrebasablemente independientes de sus formulaciones teóricas, que únicamente facilitarían las bases para un laxo "pluralismo".

No se trata aquí de menospreciar aportes por lo demás significativos al campo de la historia intelectual, sino antes bien de señalar un elemento y una conexión que, dado el carácter de estos aportes, corren el riesgo de perderse de vista: que Kracauer es un crítico del capitalismo desarrollado y que la peculiaridad de su crítica resulta de un estudio realista del objeto. Realista no remite, aquí, a un modo histórico de operaciones retóricas que simulan inmediatez referencial, como en la conocida definición de Roland Barthes, que limita la realia en literatura al inconmovible rigor del signo lingüístico de una parte y las leyes históricas de la retórica de otra (BARTHES 1994: 186s.), sino a la elevación consciente del objeto en tanto prius ontológico. Esto conduce, entre otras cosas, a una revisión del tan mentado individualismo irreductible del crítico Kracauer. Frederic Jameson ha insistido en el carácter dialéctico de esta comprensión realista, que

no es en absoluto un pensamiento personal; por el contrario, equivale a una forma de que cierto tipo de material se eleve a la apercepción, no solo como objeto de nuestro pensamiento, sino también como un conjunto de operaciones mentales propuestas por la naturaleza intrínseca de ese objeto determinado. (JAMESON 2016: 249) 
CHICOTE, Francisco M. G. - Objeto y sujeto en Sigfried Kracauer

Se trataría de explicitar el modo en que el ejercicio crítico de Kracauer supone un pase a conciencia, una historia subjetiva de formas objetivas de existencia y en qué medida dicha concientización implica un factor necesario en la intervención sobre el objeto, una modificación de su forma objetiva hacia formas más humanamente dignas. Lukács ha subrayado el carácter práctico y dignificante de la aproximación realista sobre el objeto en su Estética de 1963: "la dedicación incondicional a la realidad y el apasionado deseo de superarla van juntos" (LUKÁCS 1982: II, 227) y Hans Heinz Holz ha señalado el arraigo de esta relación general en el metabolismo simple del ser humano con la naturaleza: "Las posibilidades que se encuentran en el material son sus esencias, y la invención es una mímesis de estas esencias. En la medida en que imita sus esencias ocultas, el hombre vence en astucia a la naturaleza" (HoLz 2015: 80s.). Kracauer, que no demostró mucho aprecio por la obra del Lukács maduro, se manifiesta, sin embargo, en este aspecto de una manera aún más radical que el húngaro: "América" dice en 1925, con relación a la alienación moderna, "recién desaparecerá cuando se conozca a sí misma" (KRACAUER 2011b: 238).

\section{El sujeto como prius}

En el decurso del desarrollo intelectual de Kracauer, los mediados de la década de 1920 marcan su giro realista. Hasta ese momento, el filósofo, que contaba con un buen número de tratados monográficos y varios ensayos publicados, compartía con los enfoques posmodernistas de nuestra época la certeza de que las formas judicativas son en última instancia incumbencia del polo subjetivo. Naturalmente, tal idea no echaba raíces en el suelo fragmentario y descentrado de las teorías contemporáneas, sino en el edificio de concepciones idealistas propias de la Kulturkritik, la filosofía de la vida y el neokantismo del período guillermino. La situación de Kracauer en este complejo teórico presenta empero un rasgo original: sus lecturas de las tempranas teorías lukácsianas sobre la novela y la tragedia, por un lado, y de las esferas de existencia de Søren Kierkegaard, por el otro, condicionaron significativamente sus primeros ensayos y tornaron inviable cualquier compromiso con acaso el factor más sobresaliente de la teoría social de este complejo: la concepción antropológica de la "crisis de la cultura", cuyo ejemplar más destacado es el de Georg Simmel.

Pandaemonium, São Paulo, v. 23, n. 39, jan.-abr. 2020, p. 57-85 
Esto se manifiesta ya en su crítica de la filosofía de la vida. Para el joven Kracauer, la realidad social en el capitalismo desarrollado constituye una instancia intermedia entre dos esferas: por un lado, una forma de existencia religiosa, pretérita y superior, en la que el sentido era inmanente, y el individuo era uno consigo mismo, sus congéneres y Dios; por el otro, una forma presente, progresivamente atomística de existencia racional, carente de sentido, dios y personas auténticas. No debe menospreciarse que se trata, aquí, de una caída cualitativa y existencial de una esfera a la otra: las numerosas y tempranas impugnaciones de Kracauer a las actitudes de cuño romántico prueban que este concebía cualquier actitud de "retorno" a una comunidad llena de sentido no solo imposible, sino también éticamente dudosa. ${ }^{4}$ A su vez, sus estudios sobre fenómenos de la esfera "degradada" se fundan en una epistemología de la nostalgia: las determinaciones desprovistas de sentido pertenecientes a las esferas inferiores se tornan plausibles de ser captadas por el sujeto solo de un modo teórico y en virtud de su traducción en determinaciones correlativas llenas de sentido, que alguna vez existieron concretamente en las esferas superiores y que de algún modo permanecen en individuos que poseen una trabazón interior armoniosa y tensa de sus capacidades. He aquí el sujeto como prius, la centralidad del concepto de personalidad: hasta su giro realista, el filósofo enfatizaba la actualidad de esta categoría en tanto forma individual de resistencia y conocimiento. Así aparece, por ejemplo, en ensayos como "Deutscher Geist und deutsche Wirklichkeit" (Espíritu alemán y realidad alemana), de 1922, o "Die Reise und der Tanz" (El viaje y la danza), de 1925, en los que el cuño diltheyano de la noción de personalidad se destaca de manera inequívoca. En el último, Kracauer celebra la resistencia conservadora, irracionalista y elitista que los "hombres reales" oponen frente a la progresiva racionalización del tiempo y el espacio, encarnadas respectivamente en los tipos modernos y en boga de danza y de viaje:

El hombre real, que no ha abdicado hasta el punto de convertirse en figura de un engranaje mecanizado, se opone a la disolución en el espacio y el tiempo. [...] En cuanto que existente es, propiamente hablando, ciudadano de dos mundos o, mejor: existe entre ambos mundos; implicado en la vida espacio-temporal a la que no se ha sometido, se orienta hacia el más allá, donde todo aquí encontraría su sentido y su conclusión (KRACAUER 2006a: 189s.).

\footnotetext{
${ }^{4}$ A comienzos de la década de 1920, Kracauer rechazaba cualquier empresa para "mejorar el mundo con medios políticos". "Mientras el fundamento religioso siga faltando", le escribió a Margarete Susman en 1920, "no tiene relevancia quién realmente domine" (17 October 1920, Kracauer to Susman, DLA).
}

Pandaemonium, São Paulo, v. 23, n. 39, jan.-abr. 2020, p. 57-85 
CHICOTE, Francisco M. G. - Objeto y sujeto en Sigfried Kracauer

Kracauer vincula los atributos políticos de una personalidad con la praxis artística: "La necesidad que tiene el aquí respecto de tal complemento se expone en la obra de arte", agrega inmediatamente después en el pasaje citado. Así, revisita un elemento decisivo de la filosofía de la vida: de un modo que allanó el camino hacia la ulterior estetización de la política, primero Wilhelm Dilthey (1921) y luego Simmel (2003) insisten en el carácter estético que subyace la capacidad de la personalidad para oponerse a los procesos de alienación moderna en las esferas políticas y económicas. Sin embargo, se distancia de ambos pensadores en la medida en que no deriva, como aquellos, la creatividad artística de la incesante plétora del flujo vital, sino que afirma que el modo por el que el arte hace inteligibles las miserias sin sentido de la cotidianidad es la capacidad limitante, negativa de la forma. Kracauer valúa el trabajo estético en virtud de su forma, esto es en virtud de su capacidad para oponer y limitar: "únicamente la formación [Gebilde] estética, que torna proyectable la diversidad por medio de su dación de forma [Formung], permite la manifestación de la correspondencia [entre una y otra esferas]" (KRACAUER 2006b: 130).

En esta cuestión, cree haber desarrollado lógicamente la tesis principal de $L a$ teoría de la novela de György Lukács. Con relación a los "conceptos” de plenitud y carencia de sentido, que marcan en el ensayo del húngaro los dos polos históricos de la épica grande, escribe Kracauer a Leo Löwenthal en marzo de 1922 que estos "prestan empero un excelente servicio si se los modifica como conceptos límite epistemológicos" (LÖWENTHAL y KRACAUER 2003: 42). ${ }^{5}$ Independientemente de la justeza de este juicio, es un hecho que, para Kracauer, la carencia de sentido propia de la cotidianidad capitalista puede ser limitada por medio de la forma estética, lo que garantiza la posibilidad de la traducción. Mientras que en la esfera pasada, superior, el sentido era inmanente a las cosas, este solo puede ser puesto "desde arriba" en la esfera inferior gracias a correspondencias que resultan entre dos naturalezas cualitativamente diferentes y que solo pueden ser divisadas por la personalidad. Por ejemplo, el elemento "a", racional, carente de sentido, puede tornarse inteligible recién cuando la persona lo comprende

\footnotetext{
${ }^{5}$ La modificación epistemológica de las nociones de Lukács es señalada también en la línea inaugural de la Sociología de 1922 de Kracauer: "El concepto de 'época llena de sentido', que corresponde a un determinado enfoque metafísico básico, cumple únicamente el rol en las siguientes consideraciones de un concepto límite propio de la crítica del conocimiento. Por lo que sé, el primero en acuñarlo fue Georg v. Lukács en su escrito [...] La teoría de la novela, sin por cierto haber agotado allí su contenido de crítica del conocimiento" (KRACAUER 2006b: 12).
}

Pandaemonium, São Paulo, v. 23, n. 39, jan.-abr. 2020, p. 57-85 
CHICOTE, Francisco M. G. - Objeto y sujeto en Sigfried Kracauer

como un correlato del elemento "A" de la esfera superior, pero mientras que " $A$ " es " $A$ " por su propia legalidad, "a" es "a" en virtud de la posición que asume frente a "b", "c", etc. dentro de los límites de una formación cerrada. Sin el atributo relacional de la forma estética, la traducción resulta imposible.

Kracauer quiso probar esta teoría suya de la traducción estética en un tratado filosófico que escribió entre 1922 y 1925, pero que nunca publicó, acaso porque su giro realista ya estaba en curso por entonces. El tratado aborda un objeto de la modernidad que hasta entonces había atraído poca atención “intelectual”: las narraciones de detective. Recurriendo a nociones de Simmel, Lukács y Kierkegaard, el filósofo sostiene allí que los relatos de detective tornan inteligible la sociedad completamente racionalizada, cada vez más actual, de la esfera inferior gracias a la traducción estética:

La formación [Formung] estética es capaz de conferirle a la vida desrealizada, que ha perdido la facultad de dar testimonio de sí, una suerte de lenguaje. [...] Cuanto más profundamente va cayéndose la vida, tanto más precisa de la obra de arte, que rompe el sello de su hermetismo y ajusta sus elementos de tal modo, que estos, que yacen dispersos el uno junto al otro, se colman de relaciones. La unidad de la formación [Gebilde] estética, el modo en que distribuye los pesos y vincula los eventos, hace hablar al mundo que nada dice (KRACAUER 2006b: 117).

El tratado arroja luz sobre el modo peculiar con que Kracauer aborda un derivado conceptual de la Kulturkritik: los estragos perpetrados por el modo de producción capitalista sobre las personas son denunciados bajo el rótulo de la "crisis de la cultura". ¿Pero cómo puede comprenderse la peculiaridad de Kracauer? Al igual que la tragedia de la cultura de Simmel, la "sociología" de Kracauer depende de un sujeto que se pone lógicamente antes de la objetividad; la prioridad de nociones exclusivamente idealistas, centradas en el sujeto, tales como comunidad, interioridad, personalidad, cultura, etc. no se sostendría, pues, de otra manera. De manera coherente, Kracauer incluso concibe la modernidad como la desaparición progresiva de la actualidad de los valores, y el correspondiente incremento progresivo de la dominación de la facticidad. Tal progresión, cristalizada por Simmel como la prioridad del espíritu objetivo sobre el subjetivo, coloca lógicamente un elitismo irracionalista a la vez como premisa y derivado. Sin embargo, la teoría de Kracauer de la racionalización progresiva se sustenta en una filosofía de la historia, no en una celebración antropológica del individuo moderno: se sigue de ahí que 
CHICOTE, Francisco M. G. - Objeto y sujeto en Sigfried Kracauer

su determinación básica sea caída, no expresividad. ${ }^{6}$ Volviendo sobre modas del romanticismo decimonónico, Kracauer señala la Reforma luterana como el punto de inflexión histórica, el inicio de la decadencia. Comprende el "giro del espíritu alemán (como el europeo en general) desde la Reforma" en términos de una "pérdida gradual de la fe en la verdad incondicionada y el carácter absoluto de la sagrada doctrina de la Iglesia y la consecuente disolución de la unidad cósmica, la conexión universal (Weltzusammenhang)" (KRACAUER 2011a: 366). La “conexión universal”, una determinación que anidaba y permitía categorías basadas en la unidad orgánica tales como "comunidad", "personalidad", "interioridad", etc., cae presa ahora de un "proceso de desintegración"(Zersetzungsprozess)" por el que "se ha desmoronado pieza a pieza" "el omnicomprensivo edificio de la Iglesia" al punto de que "no queda nada más que pueda ser desintegrado" (KRACAUER 2006a: 131).

Desligada de sus marcos espaciales y temporales otrora significativos, la realidad es ahora vaciada de sustancia y dispersada en infinitas partículas iguales, que son puestas en movimiento en un "espacio vacío" "unidimensional" por una "ratio emancipada" que solo da cuenta de sí misma (KRACAUER 2006b: 118-122). El espíritu de esta ratio es movimiento sin fin: forma "mosaicos arbitrarios, pero siempre calculables" (KRACAUER 2006b: 120) que, apenas se establecen, vuelven a disolverse para formar otros nuevos. La configuración que resulta de las partículas en eterno movimiento solo es significativa para la ratio que las mueve. De acuerdo con Kracauer, la metáfora del mosaico arroja luz sobre la esencia fundamental del capitalismo monopólico: como tal, adquirirá esta metáfora una posición central luego de su giro realista. Para el "joven” y conservador Kracauer, el mosaico nunca aparece como tal por dos motivos. Primero, porque el proceso de caída no se halla consumado enteramente; desigual es la característica del proceso de racionalización en la instancia intermedia, debido tanto a su carácter gradual (id est histórico) como a la imposibilidad fáctica de una "persocialización” (Vergesellschaftung) total: esta forzosamente equivaldría a la muerte (de ahí que Kracauer insista en el hecho de que la ratio "se cree" emancipada). En segundo lugar, porque aquellos segmentos de la realidad que han sido efectivamente racionalizados asumen un aspecto de rigidez, y de

\footnotetext{
${ }^{6}$ Este es el caso en Simmel, quien circunscribe la crisis de la cultura -es decir, la crisis de la existencia humana- a un conflicto trágico entre dos principios irreconciliables: la inclinación expresiva de la vitalidad del alma y el carácter pasivo, muerto, fáctico de los medios objetivos en los que el alma ha forzosamente de expresarse. Esta conflictividad básica entre valores y objetos acompaña toda la producción teórica del filósofo, desde su Filosofía del dinero, de 1900, hasta sus consideraciones metafísicas póstumas.
} 
CHICOTE, Francisco M. G. - Objeto y sujeto en Sigfried Kracauer

ese modo aparentan estar colmados de sustancia. En la sociología de Kracauer, este proceso de falsa pero aparente sustancia lleva el nombre de "alegoría": esta "encarna conceptos universales que han perdido su ser y su capacidad simbólica, dado que no pueden ser experienciados en la relación [Beziehung] y, ahora, como ídolos congelados, han de perdurar en la configuración que los fija" (KRACAUER 2006b: 141s.).

Al ser alegórica la forma fenoménica del mosaico, el sujeto cognoscente se pone sobre sus hombros dos tareas diferentes, pero vinculadas entre sí. Por un lado, se trata de revelar el carácter verdaderamente alegórico de lo que aparece como sustancia. La crítica ideológica a la que Kracauer somete el Thomas Münzer, teólogo de la revolución de Ernst Bloch, de 1921, o sus impugnaciones del “clique” mesiánico en torno al Freies Jüdisches Lehrhaus se basan en esta actitud; la sustancia objetiva sobre la que estas teorías del cambio político o ético se cimentan es, simplemente, apariencia. ${ }^{7}$ Por otro lado, se trata de examinar las leyes del mosaico donde quiera que este aparezca expuesto en superficie. Kracauer afirma que tal es el caso de la novela de detective, en la medida en que esta "ofrece una imagen que es lo suficientemente alarmante: ofrece un estado de la sociedad en el que el intelecto sin ataduras ha finalmente triunfado" (KRACAUER 2006b: 107). Esta doble tarea será el antecedente inmediato sobre el que se fundará, más tarde, una verdadera “doble lucha”, para utilizar una frase con la que Lukács designará, a partir de la década de 1930, la actitud realista: contra los resabios regresivos y contra toda conciliación con el presente (LUKÁCS 2011: 48).

La noción de "vida", que representa una determinación básica de la filosofía "tardía" de Simmel, constituye un caso adecuado para examinar el mosaico, pues no sería, como lo supone el filósofo de Estrasburgo, la energía fundamental del mundo, sino un derivado del capitalismo desarrollado. En un tratado sobre Simmel de 1919 que, en buena medida, ha sido dejado de lado por la crítica, ${ }^{8}$ Kracauer define la vida a la vez como un

\footnotetext{
${ }^{7}$ En una carta a Leo Löwenthal, Kracauer afirma que "[Franz] Rosenzweig balbucea sobre Dios y la Creación como si hubiese estado allí, e incluso [Martin] Buber es gnóstico y místico. [Max] Scheler lo hace con la fenomenología y Bloch es totalmente inoportuno [...] En este aspecto, mi catequismo es muy claro: creo que un ser superior domina sobre nosotros, y que somos criaturas $\mathrm{y}$, por lo tanto, no tenemos acceso a los misterios del creador. Rechazo firmemente cualquier declaración sobre el comienzo o el fin del mundo, etc." (LÖWENTHAL y KRACAUER 2003: 271).

${ }^{8}$ En su análisis de esta monografía, Vedda (2016) afirma que la propuesta epistemológica, portadora de un consciente carácter político, inaugurada por Kracauer a partir de 1926 implica una recuperación crítica de ciertos factores simmelianos, tales como la perspectiva del "peregrino". "Es indudable", concluye Vedda con relación a la peculiar propuesta redentora de Kracauer, "que entre los antecesores de esta labor utópica se encuentra en un lugar destacado Georg Simmel” (2016: 269).
}

Pandaemonium, São Paulo, v. 23, n. 39, jan.-abr. 2020, p. 57-85 
CHICOTE, Francisco M. G. - Objeto y sujeto en Sigfried Kracauer

reflejo subjetivo deformado de la ratio y como un instrumento ideológico por medio del cual esta confirma su yugo sobre el individuo.

De tres maneras se establece esta relación crítica entre la categoría fundamental de la filosofía de la vida y el mosaico. En primer lugar, Kracauer afirma que la concepción general del "flujo de vida" en tanto energía subyacente de las cosas tiende a hacer de la intensificación el criterio decisivo para el conocimiento de lo bueno, bello y verdadero, pues cada una de estas determinaciones se concibe, en última instancia, como quantum intensificado de la vida. La intensificación es empero una noción relativa: presupone como tal un desarrollo desigual de las facultades expresivas del ser humano, descansa, en otras palabras, en un proceso alienante de auto-objetivación que Kracauer vincula explícitamente con el capitalismo desarrollado. Allí, el "despliegue [de un hombre]"

no se lleva a cabo como lo requiere su esencia a partir de sí misma, es decir multidireccionalmente y trasponiendo cada necesidad básica verdadera, sino que solo algunas de las capacidades anímicas hallan vías en las que pueden fluir hacia fuera, marcadas de valor. [...] Dado que el capitalismo motiva a los hombres [...] a una formación esencial totalmente unilateral, les es a estos perceptible la energía con la cual actúan (KRACAUER 2004b: 266).

El segundo elemento en común entre la noción de vida y la ratio capitalista se vincula con su básica indiferenciación. La "vida" se torna susceptible de experiencia una vez que la civilización (como forma existencial opuesta a la cultura) reduce todo producto cualitativamente único a mera determinación de cantidad, lo que a su vez implica que el proceso de producción sea comprendido también en términos cuantitativos:

como consecuencia del orden económico capitalista, el valor de sí [Selbstwert] de numerosas cosas creadas por el espíritu humano y la mano humana es sustraído y en su lugar únicamente sus precios nos indican qué significado tienen ellos para nosotros. Si los resultados de nuestra actividad han de ser totalmente ponderados entre sí con arreglo a cifras, también nuestra actividad misma parece siempre de una esencia única y solo diferente con arreglo a su intensidad (KRACAUER 2004b: 267).

Kracauer llama en efecto la atención sobre una "correspondencia" entre las leyes preeminentemente formales y lógicas del capitalismo y una "energía pura, sin cualidad" que se coloca en la Filosofía de la vida como denominador común de todas las cosas. Esto conduce a la tercera relación: del mismo modo que la siempre creciente -y ciertamente fatal- dinámica de valorización allana el camino para su propia reproducción, la intensificación de la vida acarrea una "sed" de ella que nunca podrá encontrar 
CHICOTE, Francisco M. G. - Objeto y sujeto en Sigfried Kracauer

satisfacción: la comprensión deformada de determinaciones sociales en términos de "flujos de vida" no solo refleja, sino que también estimula la subyugación por medio del consumo:

Cuanto más devienen [los hombres] esclavos de este sistema, tanto más se apodera el alma de la ambición de desplegarse en el sentido de la idea capitalista. Si el sistema prevalence sobre las restantes ambiciones, el hombre que se halla dominado por él puede que no se satisfaga fundamentalmente, le falte a su voluntad, pues la posibilidad de la satisfacción. Se mueve, pues no puede hacer otra cosa que moverse, y toda meta que cierra el horizonte interior desaparece de su vista (KRACAUER 2004b: 267).

Kracauer divisa así el elemento decisivo para la alienación característica de la fase monopólica del capitalismo: el enturbiamiento debilitante de la posición teleológica, factor rector de la praxis humana y condición necesaria para el devenir consciente de la esencia genérica de la humanidad. En su ensayo sobre la narrativa de Franz Kafka, Carlos Nelson Coutinho ha ofrecido precisamente esta clave para la caracterización del mundo plasmado por el autor de Praga: la transición histórica de formas más simples del modo de producción capitalista, que permitían "un espacio de maniobra relativamente amplio" y que solo imprimían su necesidad "en última instancia” - es decir, por ejemplo, mediante la frustración del resultado del accionar heroico-individual presente en ciertas novelas del siglo XIX-, hacia determinaciones del capital monopólico, en el que "la necesidad de la 'fuerza objetiva' que niega la libertad individual [...] se impone cada vez más como una 'primera instancia', como una experiencia inmediata ya en el seno de la vida cotidiana" puede ser comprendida como una agudización del proceso por el cual el modo de producción capitalista enajena, según Marx, la capacidad de formular finalidades (COUTINHO 2005: 127ss.). Kracauer parece insinuar, ya en 1919, la estrecha coordinación recíproca entre debilitamiento de la posición de fines, crecimiento de la dinámica de valorización y administración del consumo: "Todo despliegue de fuerza no tiene en el fondo ya meta alguna que concierna al alma como totalidad, se ha tornado energía que se agita ilimitadamente sin sentido" (KRACAUER 2004b: 267). Esta temprana crítica de la filosofía de la vida muestra en qué medida una perspectiva histórica separa radicalmente a Kracauer de Simmel, al punto de que tal clivaje no solo cimenta la comprensión del carácter histórico e ideológico de la noción de vida, sino que también posibilita la recuperación crítica de ciertos elementos presentes en Simmel para restablecer el eje cardinal de la crítica marxiana del capitalismo: el concepto de valor. 


\section{Crítica ideológica}

Con todo, esta crítica de las relaciones sociales en el capitalismo desarrollado sigue por los carriles de un esquema epistemológico idealista-subjetivo, que rechaza el carácter prioritariamente objetivo de sus herramientas. Las circunstancias biográficas en las que Kracauer dio un giro realista han sido documentadas con cierto detalle: giran en torno a una discusión de varios años con las concepciones de tinte mesiánicas de Martin Buber y Franz Rosenzweig. Hacia 1926, Kracauer comprendió que el compendio axiológicamente cargado de categorías con las que él había cimentado la posibilidad de conocimiento y sus rivales su ética mesiánica "corto-circuito" (KRACAUER 2011a: 390) no era un prius, sino en rigor una constelación concretamente histórica de nociones ideológicas nutridas por un sector social que ahora se encontraba, debido a los procesos del capital monopólico, en franca descomposición: los sectores medios alemanes decimonónicos. Así lo dice en su polémica reseña de 1926 sobre la traducción que Buber y Rosenzweig hacen del texto bíblico: el origen de valores supuestamente a-históricos presentados por la nueva versión es, para Kracauer, "obvio":

provienen del emprendimiento mitológico y del arcaizante neo-romanticismo de finales del siglo XIX, mantenidos por un sector medio cultivado necesitado de respaldo espiritual y que por entonces podrían haber poseído cierta realidad concreta debido a su adecuación a la realidad social (KRACAUER 2011b: 380).

"Respaldo spiritual" remite indirecta pero inequívocamente a la temprana teoría de la novela de Lukács, que Kracauer reseñó en 1921, un año después de que Paul Cassirer editara en Berlín el ensayo en formato de libro. Desarrollando una comprensión propia de Hegel, el joven Lukács afirmaba allí que la situación subjetiva propia de la sociedad burguesa proviene de un "desamparo trascendental” (LUKÁCS 1985: 308), de una falta de "conexión" que acarrea diferentes modos históricos de alienación subjetiva. Como Vedda (2010) y Carlos Eduardo Jordão Machado (2011) han sostenido, la noción general de desamparo como signatura saliente de la vida humana en la modernidad penetra toda la obra de Kracauer. ${ }^{9}$ En su reseña sobre la Biblia en alemán, la comprensión de que el sujeto

\footnotetext{
${ }^{9}$ Löwenthal subraya la importancia que tuvo, para "todos ellos [uns alle]" el ensayo de Lukács. En un discurso de 1990, dice sobre el libro que "era para todos nosotros un libro de culto que, prácticamente, conocíamos de memoria" (LÖWENTHAL Y KRACAUER 2003: 271); y en relación con Kracauer, agrega más tarde que este "se designaba en cierto sentido como 'desamparado' [...] En octubre de 1923, en ocasión de la boda con mi primera esposa, recibí una carta de felicitaciones en un sobre decorado por Kracauer y Horkheimer con el remitente 'Cuartel general de la oficina para el bienestar de los desamparados

Pandaemonium, São Paulo, v. 23, n. 39, jan.-abr. 2020, p. 57-85
} 
CHICOTE, Francisco M. G. - Objeto y sujeto en Sigfried Kracauer

se halla históricamente condicionado por la estructura objetiva se percibe en la impugnación del presunto carácter ahistórico -no alienado, auténtico- del "yo privado" burgués: "su irrealidad", afirma Kracauer, "revela el gesto romántico de la traducción. Su efecto estético la caracteriza a ella como un síntoma de la huida, y a lo privado como un refugio" (KRACAUER 2011b: 380ss.). Desde mediados de la década de 1920, el desamparo no es más para Kracauer un corolario de la pérdida de relación, una consecuencia desafortunada de la caída del hombre, sino más bien el resultado del proceso moderno de racionalización, que Kracauer concibe en términos ilustrados en tanto "salida" de la existencia mítica y retroceso efectivo de las barreras naturales. Se sigue de ahí que todo el marco epistemológico negativo con el que se había acercado hasta entonces al ser social sea ahora descartado en tanto constructo ideológico. Theodor W. Adorno documentó el giro teórico de su amigo en las líneas iniciales de una carta de 1926: "Querido Friedel [=Kracauer]: Te saludo en la época de la caída, que es una categoría positiva" (ADORNO 2008: 123).

El proceso de racionalización moderna es para el nuevo Kracauer, más allá de los impulsos ilustrados de su concepción, axiológicamente ambiguo. En la medida en que libera a la humanidad de las formas mitológicas de organización, coloca la conciencia genérica como posibilidad objetiva por primera vez en la historia. Sin embargo, la forma histórica capitalista de este proceso, que Kracauer denomina ratio, es una "razón enturbiada" (2006, p. 265) que no solo no da voz al género que ella misma pare, sino que también coloca a este en las garras de una suerte de recidiva mitológica-ciertamente nueva en su tipo y masivamente peligrosa-. La formulación teórica más clara de este proceso aparece en dos ensayos de 1927: "El ornamento de la masa" y "La fotografía". Permítase citar a fines ilustrativos un extenso pasaje del primero -cuyo valor teórico en el desarrollo intelectual del autor ha sido puesto en entredicho por intérpretes posmodernistas debido a un presunto tinte "especulativo" (cf. BARNOUW 2009: 15 y 21; MÜLDER-BACH 1998: 12 y 14)- no solo para captar los términos de la ambigüedad, sino

trascendentales', y más abajo con la letra de Teddie [=Adorno]: 'Kracauer y Wiesengrund: Dirección general de la oficina para el cuidado de desamparados trascendentales'. Naturalmente, era una referencia a La teoría de la novela, de Lukács, pero el 'desamparo trascendental' siguió siendo una categoría apropiada para Kracauer” (LÖWENTHAL Y KRACAUER 2003: 275s.). 
también para comprender el cambio de signo que sufre la noción de caída y desintegración:

La época capitalista es una etapa en el camino del desencantamiento. El pensamiento subordinado al actual sistema económico ha posibilitado una dominación y un aprovechamiento de la naturaleza cerrada en sí, como ningún tiempo anterior lo había logrado. Lo decisivo, sin embargo, no es que este pensamiento capacite para la explotación de la naturaleza -si los hombres fuesen solo explotadores de la naturaleza, esta habría vencido sobre sí misma-, sino que se hace cada vez más independiente de las condiciones naturales y abre así un espacio para la intervención de la razón. A su racionalidad, procedente en parte, aunque no solo, de la razón de los cuentos de hadas, hay que agradecer las revoluciones burguesas de los últimos ciento cincuenta años, que han ajustado las cuentas con las fuerzas naturales de una Iglesia enredada en lo mundano, de la monarquía y de la condición feudal. La imparable descomposición de estos y otros vínculos mitológicos es la felicidad de la razón, pues el cuento de hadas solo se realiza en los lugares de desintegración de las unidades naturales. Con todo, la ratio del sistema económico capitalista no es la razón misma, sino una razón enturbiada. Desde cierto punto de vista, abandona la verdad de la que participa. No incluye al hombre. Ni el proceso de producción está regulado en función del respeto por él, ni la organización económica y social se construye sobre él, ni en ninguna parte en absoluto es el fundamento humano el fundamento del sistema (KRACAUER 2006a: 265s.).

Ahora bien, el "fundamento humano" no es ya para Kracauer ningún concepto apriorístico: en consonancia con la línea crítica inaugurada por la reseña comentada arriba, en la que se les reprochaba a Buber y Rosenzweig la hipóstasis abstracta de un concepto acrítico, ahistórico de sujeto, se afirma aquí que la esencia humana ha de consumarse por medio del proceso de racionalización, que el capitalismo a la vez intensifica y entumece:

pues no es de eso de lo que se trata, de que el pensamiento capitalista deba cuidar del hombre como una criatura históricamente desarrollada, que deba dejarle sin dirimir como personalidad y satisfacer las exigencias de su naturaleza. Lo que los representantes de esta concepción reprochan al capitalismo es que su racionalismo violenta al hombre, y esperan con impaciencia el nuevo advenimiento de una comunidad que salve lo presuntamente humano mejor de lo que lo hace la sociedad capitalista. Prescindiendo del efecto retardatario de tales formaciones regresivas: se les escapa el núcleo mismo de la debilidad del capitalismo. Este no racionaliza demasiado, sino demasiado poco. El pensamiento del que es portador se opone a la consumación de la razón que habla desde el fundamento del ser humano (KRACAUER 2006a: 266).

El interés por una conceptualización realista del ser humano ocupa profundamente a Kracauer durante estos años. Ante todo, se sabe gracias al epistolario conservado con Bloch que, para finales de 1926, planeaba tener listo "un pequeño tratado sobre el concepto del ser humano en Marx" (en BLOCH 1985: I, 284). La monografía no fue realizada, pero el problema se halla en el centro de su primera novela, Ginster. Escrito 
CHICOTE, Francisco M. G. - Objeto y sujeto en Sigfried Kracauer

por él mismo, que Kracauer redactó a lo largo de 1927. Vedda (2011) ha sugerido en relación con la figura del protagonista, el "aspecto más saliente y comentado" de la novela, que esta sea comprendida como una "negación del carácter" (126), en cuanto no se realiza "refugiándose en un culto anacrónico de la personalidad individual y privada" ni en "episodios epifánicos de encierro en la interioridad" (128). No es arbitrario este hallazgo de Vedda: la destrucción de nociones que "amenazan la verdad" tales como "personalidad, interioridad, tragedia", es decir "valores de la cultura que se han vuelto irreales" (KRACAUER 2004a: 210), ha de ser para Kracauer uno de los dos objetivos de la gran literatura; el otro es "restablecer la imagen del ser humano" (KRACAUER 2011c: 141s.).

Aquí es preciso detenerse en otro concepto que también sobrevive, ciertamente modificado, su giro realista: el de alegoría. "En el plano de la alegoría" -se lee en el ensayo sobre la fotografía de 1927- "el pensamiento conserva y utiliza la imagen como si la conciencia vacilase en rechazar el envoltorio" (KRACAUER 2006a: 294s.). Con este término se designan conceptos que asumen apariencia mítica y que son movilizados por anticapitalismos de tinte romántico que no distinguen entre ratio y razón: de manera general, Kracauer señala en este gesto a la filosofía de la vida y al esoterismo vitalista del círculo de Stefan George (KRACAUER 2011a: 379), y en 1931 analiza detenidamente un órgano de difusión de lo que post festum sería llamado "revolución conservadora", la revista Die Tat. Kracauer le reprocha a los colaboradores de este periódico no tanto su incapacidad para discernir entre ratio, razón e intelecto en su cruzada contra la "pobreza material del presente" (KRACAUER 2011c: 719s.) como su desconocimiento de que las nociones que defienden resultan de y reflejan una forma histórica determinada del proceso de racionalización capitalista. En el caso de los conceptos axiológicamente cargados de este círculo -el Volk, el mito, la personalidad- se trata de formas ideológicas que reflejan la "mala" racionalización a la que han sido sometidos los estratos medios alemanes, cuya resistencia a la proletarización debe forzosamente vincular, de manera abstracta y contradictoria en virtud de su irrealidad, una vuelta al carácter orgánico natural con una defensa de valores del capitalismo liberal ya realmente inexistente. El problema de estos círculos, cuya virtud es la de expresar la contradictoria situación ideológica de una clase intermedia que flota ahora en el vacío, es que no reconocen que la alegoría es una forma de existencia objetivamente necesaria de la ratio capitalista:

Pandaemonium, São Paulo, v. 23, n. 39, jan.-abr. 2020, p. 57-85 
CHICOTE, Francisco M. G. - Objeto y sujeto en Sigfried Kracauer

[Esta ratio] tiene una afinidad mucho más profunda con la barbarie que con la razón, inclusive la razón liberal. La ratio es [...] el exponente de fuerzas naturales ciegas, y nada sería más absurdo y al mismo tiempo inútil que querer combatir la ratio con ayuda de la misma mera naturaleza que se representa en ella (KRACAUER 2011c: 735).

El insistente rechazo por parte de Kracauer a soluciones abstractas a la alienación moderna indica menos la presunta actitud celebratoria de la modernidad atribuida por algunas interpretaciones de su trabajo que una consecuente comprensión materialista del cambio social radical. $\mathrm{Si}$, como se lee en la reseña de la Biblia en alemán, "hoy el acceso a la verdad es por medio de lo profano" (KRACAUER 2011b: 385), esto se debe a que el acceso a la realidad cotidiana condiciona la realidad cotidiana y viceversa: la realidad cotidiana condiciona el acceso a ella. "Las recetas no resultan apropiadas en todo lugar, y menos que en cualquier otro en este, donde lo que importa en primera instancia es comprender una situación que apenas ha sido observada hasta ahora", advierte Kracauer al comenzar su ensayo sobre la terra incognita de los empleados comerciales, el expandido sector de servicios del capitalismo monopólico:

El conocimiento de esta situación, además, no solo es la condición necesaria para todas las transformaciones, sino que supone, ya de por sí, un cambio, ya que si la situación aludida se conoce a fondo, será preciso actuar sobre la base de la nueva conciencia conquistada acerca de ella (KRACAUER 2008: 106).

Así se manifiesta, pues, inequívocamente la "doble lucha" que comienza a mediados de la década de 1920 en la praxis intelectual de Kracauer: por un lado, combate las políticas regresivas del irracionalismo alemán develando su carácter ideológico, insoslayablemente moderno. Por el otro, emprende una crítica irreconciliable de la dinámica de valorización capitalista, que concibe -a contrapelo de las extendidas concepciones acerca del presunto dominio directo de una clase sobre otra- en términos de un mecanismo autónomo y al servicio de nadie. Sugerente en este modo de interpretación, que comparte con críticos del capitalismo desarrollado como Lukács y Kafka, es que recurra en 1931 al poema goetheano "El aprendiz de brujo" para ilustrar la dinámica expansiva del capital como un encanto que, apenas conjurado, escapa al control del aprendiz y pone en riesgo efectivo y creciente la vida entera (KRACAUER 2011c: 721). Cuatro años antes, en el ya citado "El ornamento de la masa", se leía:

[E]l proceso de producción capitalista es un fin en sí mismo. Las mercancías que pone en circulación no están realmente producidas para ser poseídas, sino a causa del beneficio, que se quiere ilimitado. Su crecimiento está ligado al de la empresa. El productor no trabaja para una ganancia privada -en los Estados Unidos, los excedentes se llevan a los 
CHICOTE, Francisco M. G. - Objeto y sujeto en Sigfried Kracauer

asilos del espíritu, como las Bibliotecas o las Universidades, en donde se hace madurar a los intelectuales que a través de su posterior actividad reembolsan con interés compuesto el dinero adelantado-, el productor trabaja para el engrandecimiento de la empresa (KRACAUER 2006a: 262).

La comprensión del carácter "natural" de este mecanismo -"natural" porque en su defectiva racionalización representa una dinámica que, al no coincidir con lo humano, adquiere una efectividad propia de determinaciones naturales- no solo permite a Kracauer divisar el arraigo objetivo de las ideologías regresivas, sino también impugnar por fútiles y peligrosos los valores del liberalismo, que han perdido sustancia histórica tras la desaparición del capitalismo liberal y operan ahora como reflejo ideológico del capital monopólico. Así sucede, por ejemplo, con la ambición, tan frecuente en los sectores medios, de una individualidad auténtica, que en la ideología de la burguesía ascendente se presenta como la trasposición en el trabajo de una inclinación interior. En la empresa moderna, empero, "[l]os puestos no son exactamente profesiones que hayan sido hechas a la medida de las así llamadas personalidades, sino puestos en la empresa, que son asignados de acuerdo con las necesidades del proceso de producción y distribución" (KRACAUER 2008: 122).

\section{El objeto como prius}

El doble frente pone, entonces, la cotidianidad como locus exclusivo de la verdad y descarta cualquier recurso idealista, sea este meramente teórico o incluya factores éticos. Esta posición en Kracauer es radical, pues condiciona la forma de su crítica y, por ende, su búsqueda de configuraciones subjetivas. Un punto de acceso para comprender la coordinación dialéctica entre categoría y objeto es el concepto de mosaico, que a partir de mediados de los años veinte designa en Kracauer tanto un estado del mundo como la forma de su conocimiento y, por ende, de su transformación radical.

Desde el punto de vista objetivo, el concepto de mosaico sufre una modificación importante respecto de lo que significaba en Kracauer antes: ya no ilustra por medio de una metáfora el estrago de la ratio, sino que pasa a designar el proceso general de retroceso de barreras naturales y la correspondiente desaparición de las formas míticas de organización social, proceso del que, como hemos visto, la ratio también participa. Kracauer encuentra una manifestación "modélica" del mosaico en los estudios de filmación de la UFA, una empresa que, durante el período de entreguerras, administraba 
CHICOTE, Francisco M. G. - Objeto y sujeto en Sigfried Kracauer

todos los factores de la industria. Al interior de los estudios de filmación se halla copiado artificialmente, el mundo en partes dispersas e inconexas: fachadas, árboles, vestidos, muebles de calicó se apilan sin sentido en los depósitos para ser montados en escena, llamados con arreglo a la conciencia humana. En el "régimen de arbitrariedad", "la naturaleza, tal como ella es, es pasada a retiro" (KRACAUER 2004a: 193s.), y el mundo es nuevamente recreado:

Las escenas son muchas; como a las piedrecillas de un mosaico se los coloca uno al lado del otro. En vez de dejar el mundo en su estado fragmentario, se reconstituye el mundo con ellas. Las cosas desligadas de la conexión son insertadas nuevamente en ella, su separación es borrada, su mueca es suavizada. De las tumbas que no han sido hechas para ser tomadas en serio se despiertan para una ilusión de vida (KRACAUER 2004a: 196).

Dos son las determinaciones objetivas del mosaico: bidimensionalidad e igualdad ciega. Como Marx en el célebre pasaje sobre "la forma de valor o el valor de cambio", que postula la historicidad del "concepto de igualdad humana" en cuanto que este aparece recién en "una sociedad donde la forma de mercancía es la forma que adopta el producto del trabajo" (MARX 1985: 74), Kracauer concibe la igualdad como consecuencia de la abstracción de las cualidades individuales que sucede en el intercambio generalizado de bienes: cada elemento vale en virtud de su equivalencia con los otros. No es fortuito entonces que por momentos pareciera querer ilustrar el proceso histórico del mosaico con un esquema -artificioso- de transición entre géneros literarios "simples": del mito (Mythos) al cuento de hadas de mentira (Lügenmärchen), y de este al cuento de hadas prototípico (Märchen).

La existencia de unidades refractarias a la equivalencia se halla representada en el mito: este "reconoce al organismo como su modelo primigenio, se quiebra con el carácter configurado de lo existente, se inclina ante el imperio del destino, en todas las esferas refleja lo dado en la naturaleza sin rebelarse contra su permanencia" (KRACAUER 2006a: 264). Con el intercambio generalizado y la lógicamente subsecuente forma mercantil de la producción de bienes, la unidad orgánica se convierte en un "revoltijo": las cosas "pierd[en] su ordenamiento original y ya no respond[en] del nexo espacial que las ligaba a un original". Resulta, entonces, una "confusión”, un "juego con la naturaleza despedazada" que "recuerda al sueño en el que se enmarañan los fragmentos de la vida diurna" (KRACAUER 2006a: 297 y 298).

Estragado su objeto, el mito cede en actualidad a otro género, el Lügenmärchen, una variante del cuento de hadas que presenta una concatenación agobiante y sin sentido 
CHICOTE, Francisco M. G. - Objeto y sujeto en Sigfried Kracauer

de objetos dispuestos caóticamente, con nulo o casi nulo ordenamiento épico. El Lügenmärchen que en la antología de los hermanos Grimm lleva el nombre de "El cuento del país de Jauja" es el utilizado por Kracauer para dar cuenta del carácter ininterrumpidamente revolucionario del capital:

En los tiempos de jauja iba yo andando y vi que en un pequeño hilo de seda estaban colgadas Roma y Letrán, y un hombre cojo, con un caballo rápido y una espada afilada, atravesaba un puente. Vi también a un joven asno con una nariz de plata, que iba persiguiendo a dos liebres veloces, y un tilo muy ancho en el que crecían tortas calientes. Luego vi una cabra vieja y flaca que llevaba encima cien carretadas de manteca y sesenta de sal. ¿No son ya suficientes mentiras? (GRIMM Y GRIMM 2009: 20; cf. KRACAUER 2006a: 275).

El mundo representado por esta variante de los cuentos de hadas es, como el mosaico del capital, tan antinatural como hostil al despliegue de la vida humana, lo que, de acuerdo con Kracauer, significa una contradicción: la ratio abstracta e indiferente al ser humano es, paradójicamente, naturaleza rediviva. Es sugestivo que el propio Marx, al emprender el análisis de la jornada laboral moderna y sus efectos destructivos, introduzca precisamente estas determinaciones y recurra a metáforas naturales para definir la dinámica de valorización del tiempo de trabajo, como si la forma histórica de emancipación de la naturaleza generara una suerte de nueva prisión natural. La "sed vampiresca de sangre viva de trabajo", la "hambruna canina de plustrabajo" no solo atrofia la fuerza de trabajo, sino que también ocasiona la muerte prematura, y pone en el horizonte lógico el fin de la humanidad (1985: 309 y 319s.). Se trata de "una arremetida violenta y desmesurada, como la de un alud", en la que todas

las barreras erigidas por las costumbres y la naturaleza, por la edad y el sexo, por el día y la noche, saltaron en pedazos. Hasta los conceptos de día y noche, de rústica sencillez en las viejas ordenanzas, se desdibujaron a tal punto que un juez, todavía en 1860, tuvo que hacer gala de una sagacidad verdaderamente talmúdica para explicar "con conocimiento de causa" qué era el día y qué la noche. El capital celebraba sus orgías (MARX 1985: 335s.).

Mientras que la contraposición entre mito y cuento de hadas de mentira sirve para comprender el vínculo entre modos de organización premodernos y modos capitalistas desarrollados, un tercer género se perfila como realización concreta de la "exigencia de la razón", pues realiza el pase a conciencia de la igualdad ciega y autómata, de apariencia $\mathrm{y}$ efectividad naturales, del mosaico-Lügenmärchen $\mathrm{y}$, con ello, lleva a cabo una transformación radical en el sentido antropológico del joven Marx (1982a: 497). El cuento de hadas de mentiras es conjurado por el cuento de hadas, que conserva de aquel 
CHICOTE, Francisco M. G. - Objeto y sujeto en Sigfried Kracauer

la superación real del organismo, pero instaura a la vez un ordenamiento épico del mundo con arreglo a las medidas del ser humano y de todas las cosas. Si el Lügenmärchen es el ámbito de la mentira y el sueño (el sujeto de la enunciación de "El cuento del país de Jauja" se queja de la sarta de mentiras que relata, sarta que recién con el "quiquiriquí" del gallo llega a su fin ${ }^{10}$, el del cuento de hadas anticipa la verdad y el despertar. La existencia consciente del género es entendida por Kracauer como un despertar del mosaico, un proceso que "conduce a través del ornamento de masas, no desde él hacia afuera":

Este proceso solo puede avanzar si el pensamiento pone límites a la naturaleza y produce al ser humano tal como es cuando el punto de partida es la razón. Entonces cambiará la sociedad. Y entonces desaparecerá el ornamento de masas y la propia vida humana asumirá los rasgos de aquel ornamento en el que esta se expresa en los cuentos de hadas frente a la verdad (KRACAUER 2006a: 274).

¿Cuál es el sujeto que ordena épicamente el "revoltijo" del mosaico? El nuevo concepto de mosaico objetivo se halla acompañado, en la praxis crítica de Kracauer, por una evaluación positiva del clown en el cine cómico: contemporánea al ensayo sobre los estudios de la UFA es una breve reseña de un cortometraje de John Blystone, The Huntsmen, de cuyo personaje resalta Kracauer el carácter "no-heroico", y su "colocarse en un tal malentendido con las cosas": "Rasgos del cuento de hadas se hallan contenidos en estos grotescos" (KRACAUER 2006a: 190). Joseph Roth (1990: 997) y Enzo Traverso (1994: 13ss.) han dado ya cuenta del interés teórico de Kracauer por los clowns como los encarnados por Buster Keaton y Charles Chaplin. Así como los cuentos hadas, las películas cómicas de estos representan un ordenamiento épico insoslayablemente inmanente -todo lo que puede expresar trascendencia, el trasfondo, la profundidad, el más allá, no existen ni siquiera como postulados- en el que la configuración humana del mundo se da, para volver al radicalismo antropológico del joven Marx, en términos genéricos. La acción es astuta porque satisface uno actu la teleología del ser humano y la potencialidad del medio objetivo; aquel no se configura orgánicamente como personalidad misteriosa, este es elaborado con arreglo a las cualidades que le son inherentes. Un reordenamiento teleológico tal del mundo, que observa, como lo indicaría Marx, "la medida de toda especie" y "la medida inherente al objeto" (MARX 2004: 113),

\footnotetext{
${ }^{10}$ El cuento termina así: "Luego vi dos galgos, que traían un molino del agua, y una vieja desolladora decía que estaba bien hecho. Y en la corte había cuatro caballeros, que trillaban grano con todas sus fuerzas, dos cabras que calentaban la estufa y una vaca roja que metía el pan en el horno. Entonces gritó un gallo: 'Quiquriquí, el cuento se ha acabado aquíííi'”' (GRIMM Y GRIMM 2009: 21).
} 
CHICOTE, Francisco M. G. - Objeto y sujeto en Sigfried Kracauer

tiene lugar en los tricks de los personajes de los filmes cómicos (KRACAUER 2004a: 86), que eliminan sin violencia la estructura natural-trágica del ordenamiento mitológico del mundo. Vedda ha señalado la continuidad conceptual que se establece en Kracauer entre "la astucia con la que el héroe del cuento de hadas derrota a las potencias míticas" y "la función del intelectual moderno", que ha de dedicarse al "desmantelamiento de lo mitológico" (VEDDA 2011: 109).

Cuando este nuevo concepto de crítica, que se tiene por la forma consciente del condicionamiento objetivo sobre el sujeto, se vincula no ya con los sujetos literarios o fílmicos, sino más bien con la tarea de la teoría sobre el ser social, el término elegido coincide precisamente con aquel que designa el mundo: el mosaico. Así, pues, en el brevísimo pasaje programático que se halla al comienzo del estudio sobre los empleados comerciales, se postula la cuestión del "método" en los siguientes términos:

La realidad es una construcción. Ciertamente, la vida debe ser observada a fin de que la realidad se constituya. Pero esta de ningún modo se encuentra contenida en la serie de observaciones más o menos casuales que conforman el reportaje; antes bien, se halla única y exclusivamente en el mosaico que se compone a partir de las observaciones individuales, sobre la base del conocimiento del contenido de la realidad. El reportaje fotografía la vida; un mosaico como este sería su imagen (KRACAUER 2008: 117s.).

Resulta ocioso retomar aquí las interpretaciones que ven, en este pasaje, la confirmación de una perspectiva "posmodernista", o al menos la impugnación de "grandes sistemas filosóficos" (ver primera sección). El carácter construido de la realidad objetiva condiciona el carácter del conocimiento, que también ha de ser una actividad; se retoman, en este pasaje, puntos nodales de las dialécticas de Hegel, Marx y Lukács para criticar, como ellos, el desconocimiento de tal coordinación. Los polos que en las coordenadas sociohistóricas de Kracauer reciben respectivamente los nombres de "idealismo" y "reportaje" son las formas históricas correspondientes del oscilante dualismo epistemológico de la sociedad burguesa, que necesariamente vacila, al desconocer o bien el carácter objetivo del mundo, o bien su propio carácter objetivo, entre actitudes lírico-idealistas y trágico-materialistas.

¿Cuáles son las determinaciones básicas del mosaico en tanto procedimiento del conocimiento? Dúplice es el proceso desde el punto de vista lógico: a un momento de (a) desintegración conscientemente mediada le sigue otro de (b) reconfiguración irónicamente mediada. Considérense como ejemplos dos casos típicos de mosaico del Kracauer de la segunda mitad de los años veinte: "Film und Gesellschaft" (Filme y 
CHICOTE, Francisco M. G. - Objeto y sujeto en Sigfried Kracauer

sociedad), de 1927, ${ }^{11}$ y el ensayo, ya mencionado, sobre los empleados comerciales, de 1929.

En el primer caso, que constituye una exposición acerca de películas de consumo masivo, desarticula la apariencia unitaria, la cerrazón aparente y efectivamente orgánica de cada película para resaltar su carácter realmente artificioso: se descubre tras el velo de unidad armoniosamente irreductible en las películas que se dirigen al sujeto prototípico de la masa, el empleado comercial, procedimientos constructivos propios de la sociedad de clases moderna. La función de estos filmes no es ya aquella concreción de la “exigencia de la razón” que el idealismo humanista alemán había encargado al arte, sino la humillación del individuo. "Film und Gesellschaft" descompone un número finito de películas en relaciones conceptuales y explica el modo en que estéticamente tales relaciones se plasman. Esta destrucción de unidades "alegóricas" es la forma de la lucha ideológica que Kracauer emprende durante estos años: lo mismo sucede, por ejemplo, cuando Kracauer desarma el pensamiento irracionalista del círculo de Die Tat. La descomposición se halla mediada por una conciencia que elige: Kracauer retrotrae el finish -esto es, la mercancía lista para el consumo (MARX 1982b: 12)- a un momento modélico de su ensamblaje: en la conformación del mosaico, ciertos factores son conscientemente intensificados de manera tal que se resalte su carácter predominante, otros son acallados.

El momento configurador nunca impone un finish, lo que equivale a decir que nunca impone una forma de consumo (cf. MARX 1982b: 12). Por el contrario: la configuración deja en "carne viva" al mosaico. Kracauer no solo desarma su objeto, sino que lo hace de manera tal que sea difícil la eventual sutura de los desgarros ocasionados. Aquí aparece el elemento irónico que se alza como principio anticicatrizante, y que permea gran parte de la prosa ensayística de Kracauer durante estos años. Si bien tenue, la ironía kracaueriana es satírica en la medida en que, en su fracturación del finish, contrapone inmediatamente componentes esenciales con factores fenoménicos de su objeto. En su libro sobre los empleados comerciales, Kracauer opone irónicamente toda la simbología referente al tesoro axiológico de los sectores medios alemanes del siglo XIX -en el que destaca, ante todo, el valor de la personalidad orgánica, única y

\footnotetext{
${ }^{11}$ El ensayo apareció luego en la antología Das Ornament der Masse (El ornamento de la masa) bajo el título "Die kleinen Ladenmädchen gehen ins Kino" (Las pequeñas empleadas de comercia van al cine).
} 
CHICOTE, Francisco M. G. - Objeto y sujeto en Sigfried Kracauer

misteriosa- con los procesos objetivos de racionalización que atentan contra la vida de los empleados. Por ejemplo, al narrar un encuentro en "las altas esferas" de la conducción comercial de una fábrica moderna, esferas que se proponen como locus de la realización mágica de tales tesoros, Kracauer reproduce el diálogo que tuvo con el director, cuando este le muestra los protocolos de racionalización de tareas:

-Las chicas -responde- perforan solo durante seis horas, y durante las dos horas restantes trabajan en tareas de oficina. De esa manera se les evita el trabajo excesivo. Esto se realiza a través de una determinada rotación, de modo que cada empleado pasa por todos los trabajos. Además, por razones de higiene intercalamos, de vez en cuando, algunas pausas para airearse.

¿Qué organización...! Ni siquiera se olvidan de los breves lapsos de tiempo para tomarse un respiro.

-Hemos trabajado durante nueve meses para organizarlo todo -señala el director comercial-. El feje de la oficina me coloca bajo la nariz un libro enorme en el que se encuentra rigurosamente consignado, hasta el menor detalle, el plan de trabajo adecuado para la sala de máquinas.

-Si alguna vez (el Cielo no lo permita) usted cae súbitamente enfermo -le dije al jefe de la oficina-, ¿puede alguien sustituirlo de inmediato y asumir la dirección con la ayuda del libro?

-Claro que sí.

Se siente muy halagado de que se reconozca la previsión con que logró que siempre sea posible reemplazarlo (KRACAUER 2008: 131s.).

En tanto recurso propio del acervo satírico, se trata de una destrucción del objeto, de una saturación ad absurdum del carácter trascendental de la envoltura de su objeto. La ironía satírica funciona, así, como herramienta para la superficialización de contenidos profundos y su rechazo inmediato no en aras de una superioridad moral, sino sobre la base de un sujeto amoral y débil que se limita, como en los trabajos satíricos de Marx y Engels de las décadas de 1840 y 1850, a reorganizar su objeto de modo tal que este revele por sí mismo su mentira.

\section{Conclusión}

Las líneas precedentes han intentado argumentar a favor de la siguiente hipótesis: la forma que la crítica de Kracauer asume en la segunda mitad de la década de 1920 no proviene de un concepto epistemológico que niega su carácter objetivo, tal como, con arreglo a la tendencia posmodernista en las ciencias sociales, un número significativo de intérpretes han querido ver en sus obras. Por el contrario: el problema epistemológico se resuelve conscientemente en una posición ontológica que parte del reconocimiento del carácter objetivo del ser en tanto ser, lo que lleva a una doble comprensión. Por un lado, la supuesta 
CHICOTE, Francisco M. G. - Objeto y sujeto en Sigfried Kracauer

forma exclusivamente subjetiva de la facultad judicativa resulta, para retomar un juego de palabras del joven Marx, un Unwesen: a la vez un no ser y una monstruosidad. De ahí que su falsedad sea ideológica y deba ser conjurada mediante su inmersión en la serie histórica: Kracauer descubre que las variantes contemporáneas de estas concepciones epistemológicas, las que derivaban de la filosofía de la vida y la Kulturkritik, constituían expresiones fosilizadas y acríticas de la situación objetiva de los sectores medios alemanes del siglo XIX. Por otro lado, la propia forma crítica se plasma a partir del esfuerzo consciente de hacerla derivar de la estructura objetiva del mundo sobre el que se posa. De ahí que los aspectos formales de su crítica, que en su obra obtienen el nombre de "mosaico", puedan ser considerados como existencia subjetiva consciente de categorías cuya existencia objetiva también reciben el nombre de "mosaico". Esta comprensión dialéctica de la coordinación sujeto-objeto coloca a Kracauer en una tradición teórica que pasa por Hegel, Marx y Lukács, y que supone que el deseo de cambiar la realidad histórica va de la mano de su conocimiento objetivo. El elemento conector es la forma en tanto aspecto expresivo del contenido. De eso se trata el realismo.

\section{Referencias bibliográficas}

ADORNO, T. W. Briefe und Briefwechsel. Frankfurt a.M.: Suhrkamp, 2008.

BARNOUW, D. Critical realism: history, photography, and the work of Siegfried Kracauer. Baltimore: The John Hopkins University Press, 1994.

BARNOUW, D. Vielschichtige Oberflächen: Kracauer und die Modernität von Weimar. In: GRUNERT, F. et al. (ed.). Denken durch die Dinge: Siegfried Kracauer im kontext. München: Wilhelm Fink, 2009, p. 13-28.

BARTHES, R. El susurro del lenguaje: más allá de la palabra y la escritura. Traducción de C. Fernández Medrano. Barcelona: Paidós, 1994.

BLOCH, E. Briefe. 1903 bis 1975. Erster Band: Briefe von und an Ernst Mach, Georg Lukács, Annette Kolb, Johann Wilhelm Muehlon, Max Scheler und Siegfried Kracauer. Frankfurt a. M.: Suhrkamp, 1985.

ClifFORD, James. Introduction: partial truths. In: ClIFFORD, J.; MARCUS, G. E. (ed.). Writing culture: the poetics and politics of ethnography. Berkeley: University of California Press, 1986, p. 1-26.

Coutinho, C. N. Lukács, Proust e Kafka: literatura e sociedade no século XX. São Paulo: Civilização Brasileira, 2005.

DiltheY, W. Das erlebnis und die dichtung. Göttingen: Vandenhoeck \& Ruprecht, 1921.

Foucault, M. Microfísica del poder. Traducción de Julia Varela y Fernando Álvarez-Uría. Madrid: Las ediciones de La Piquita, 1979.

FRISBY, David. Fragmentos de la modernidad: teorías de la modernidad en la obra de Simmel, Kracauer y Benjamin. Traducción de Carlos Manzano. Madrid: Visor, 1992.

GEERTZ, C. The interpretation of cultures: selected essays. New York: Basic Books, 1973.

GEERTZ, C. Local knowledge: further essays in interpretative anthropology. New York: Basic Books, 1983.

Pandaemonium, São Paulo, v. 23, n. 39, jan.-abr. 2020, p. 57-85 
CHICOTE, Francisco M. G. - Objeto y sujeto en Sigfried Kracauer

Grimm, J.; Grimm, W. Cuentos completos. Traducción de María Antonia Seijo Castroviejo. Madrid: Alianza Editorial, 2009.

Hofmann, M.; KorTA, T. Siegfried Kracauer: Fragmente einer Archäologie der Moderne. Sinzheim: Pro Universitate Verlag, 1997.

Holz, H. H. El papel de la mimesis en la Estética de Lukács. In: VeddA, M.; Costa, G.; AlcÂnTARA, N. (org.). Anuario Lukács. Traducción de Francisco García Chicote. Maceió: Instituto Lukács, 2015, p. 77-96.

HorkHEIMER, M. Teoría crítica. Traducción de Edgardo Albizu y Carlos Luis. Buenos Aires: Amorrurtu, 2008.

KocH, G. Siegfried Kracauer: zur Einführung. Hamburg: Junius Verlag. 1996.

JAMESON, F. Marxismo y forma. Traducción de Cristina Piña Aldao. Madrid: Akal, 2016.

KRACAUER, S. Kleine Schriften zum Film: 1921-1927. Werke 6.1. Frankfurt a.M.: Suhrkamp Verlag, 2004a.

KRACAUER, S. Frühe Schriften aus dem Nachlaß. Werke 9.2. Frankfurt a.M.: Suhrkamp Verlag, 2004b.

KRACAUER, S. Estética sin territorio. Traducción de Vicente Jarque. Colegio Oficial de Aparejadores y Arquitectos Técnicos de la Región de Murcia. Consejería de Educación y Cultura de la Región de Murcia: Murcia, 2006a.

Kracauer, S. Soziologie als Wissenschaft. Der Detektiv-Roman. Die Angestellten. Werke 1. Frankfurt a.M.: Suhrkamp Verlag, 2006b.

KraCAUER, S. Los empleados: un aspecto de la Alemania más reciente. Traducción de Miguel Vedda. Madrid: Gedisa, 2008.

KraCAUER, S. Essays. Feuilletons. Rezensionen: 1924-1927. Werke 5.2. Frankfurt a.M.: Suhrkamp Verlag, $2011 \mathrm{~b}$.

KraCAUER, S. Essays. Feuilletons. Rezensionen: 1906-1923. Werke 5.1. Frankfurt a.M.: Suhrkamp Verlag, 2011a.

KraCAUER, S. Essays. Feuilletons. Rezensionen: 1928-1931. Werke 5.3. Frankfurt a.M.: Suhrkamp Verlag, 2011c.

LÖWENTHAL, L.; KRACAUER, S. In steter Freundschaft: Briefwechsel. Hamburg: zu Klampen Verlag, 2003.

LUKÁCS, G. La peculiaridad de lo estético. Traducción de Manuel Sacristán. Barcelona: Grijalbo, 1982.

LUKÁCS, G. El alma y las formas: la teoría de la novela. Traducción de Manuel Sacristán. Ciudad de México: Grijalbo, 1985.

LuKÁCS, G. Escritos de Moscú: estudios sobre política y literatura. Traducción de Martín Koval y Miguel Vedda. Buenos Aires: Gorla, 2011.

MACHADO, C. E. J. Das Asyl für Obdachlose und das "falsche Bewußtsein" - nach Siegfried Kracauer. Iberoamerikanisches Jahrbuch für Germanistik, Logroño, n. 5, 2011, p. 101118.

MARX, K. Escritos de juventud. Traducción de Wenceslao Roces. Ciudad de México: Fondo de Cultura Económica, 1982a.

MARX, K. Introducción. In: MARX, K. Elementos fundamentales para la crítica de la economía política (Grundrisse) 1857-1858. Traducción de Pedro Scaron. Ciudad de México: Siglo XXI, 1982b, p. 1-33. 1 v.

MARX, K. El capital: libro primero. Traducción de Pedro Scaron. Ciudad de México: Siglo XXI, 1985.

MARX, K. Manuscritos económico-filosóficos de 1844. Traducción de Fernanda Aren, Silvina Rotemberg y Miguel Vedda. Buenos Aires: Colihue, 2004.

MCDONALD, T. Introduction. In: MCDONALD, T. (ed.). The historic turn in the human sciences. Ann Arbor: The University of Michigan Press, 1996, p. 1-14.

MÜLDER-BACH, I. Introduction. In: KRACAUER, S. The salaried masses: duty and distraction in Weimar Germany. Traducción de Quintin Hoare. London: Verso, 1998, p. 1-22. 
CHICOTE, Francisco M. G. - Objeto y sujeto en Sigfried Kracauer

MÜLDER-BACH, I. El cineasta como etnógrafo: acerca de la prosa de Siegfried Kracauer. Terceira Margem, Rio de Janeiro, v. 19, n. 32, 2015, p. 20-40.

OSCHMANN, D. Kracauers ideal der konkretion. In: GRUNERT, F.; KIMMICH, D. (ed.). Denken durch die Dinge: Siegfried Kracauer im Kontext. München: Wilhelm Fink, 2009, p. 2946.

RABINOW, P. Representations are social facts: modernity and post-modernity in anthropology. In: ClifFORD, J.; MARCUS, G. E. (ed.). Writing culture: the poetics and politics of ethnography. Berkeley: University of California Press, 1986, p. 235-261.

Reynoso, C. Presentación. In: ReYnoso, C. (ed.). El surgimiento de la antropología posmoderna. Ciudad de México: Gedisa, 1991, p. 11-60.

RICOEUR, P. The model of the text: meaningful action considered as a text. New Literary History, Baltimore, v. 5, n. 1, 1973, p. 91-117.

Ricoeur, P. Estructura y hermenéutica. In: ARANZUEQUe, G. (coord.). Horizontes del relato: lecturas y conversaciones con Paul Ricoeur. Madrid: Universidad Autónoma de Madrid, 1997, p. 49-73.

ROTH, J. Werke. Köln: Kiepenheuer \&Witsch, 1990.

SAZBÓN, J. El sujeto en las ciencias humanas. In: SAZBÓN, J. Nietzsche en Francia y otros estudios de historia intelectual. Bernal: Universidad Nacional de Quilmes Editorial, 2009, p. 135-166.

SimMEl, G. Goethe. Deutschlands innere Wandlung. Das Problem der historischen Zeit. Rembrandt. Gesamtausgabe 15. Frankfurt a.M: Suhrkamp, 2003.

STALDER, H. Siegfried Kracauer: das journalistische Werk in der 'Frankfurter Zeitung' 19211933. Würzburg: Königshausen \& Neumann, 2003.

SteINMEYeR, G. Siegfried Kracauer als Denker des Pluralismus. Berlin: Lukas Verlag, 2008.

Traverso, E. Siegfried Kracauer: itinéraire d'un intellectuel nomade. Paris: La Découverte, 1994.

VedDA, M. La tradición de las causas perdidas. In: KracAuer, S. Historia. Traducción de Guadalupe Marando y Agustín D’Ambrosio. Buenos Aires: Las cuarenta, 2010, p. 9-36.

VEDDA, M. La irrealidad de la desesperación: estudios sobre Siegfried Kracauer y Walter Benjamin. Buenos Aires: Gorla, 2011.

VEDDA, M. Sobre la filosofía del desarraigo: a propósito del estudio del joven Siegfried Kracauer sobre Georg Simmel. In: VerniK, E.; BORISONIK, H. (ed.). Georg Simmel un siglo después: actualidad y perspectiva. Buenos Aires: IIGG-CLACSO, 2016, p. 261-270.

Recebido em 19 de maio de 2019 Aceito em 09 de julho de 2019 